\title{
A renewed Medication Adherence Alliance call to action: harnessing momentum to address medication nonadherence in the United States
}

This article was published in the following Dove Press journal:

Patient Preference and Adherence

7 July 2016

Number of times this article has been viewed

\author{
Leah L Zullig',2 \\ Bradi B Granger ${ }^{3}$ \\ Hayden B Bosworth ${ }^{1-4}$ \\ On behalf of the \\ Medication Adherence \\ Alliance \\ 'Center for Health Services Research \\ in Primary Care, Durham Veterans \\ Affairs Medical Center, ${ }^{2}$ Division \\ of General Internal Medicine, \\ Department of Medicine, Duke \\ University, ${ }^{3}$ Duke Heart Center \\ Nursing Research Program, School \\ of Nursing, Duke University, \\ ${ }^{4}$ Department of Psychiatry and \\ Behavioral Sciences, Duke University, \\ Durham, NC, USA
}

The problem: Nonadherence to prescription medications is a common and costly problem with multiple contributing factors, spanning the dimensions of individual behavior change, psychology, medicine, and health policy, among others. Addressing the problem of medication nonadherence requires strategic input from key experts in a number of fields.

Meeting of experts: The Medication Adherence Alliance is a group of key experts, predominately from the US, in the field of medication nonadherence. Members include representatives from consumer advocacy groups, community health providers, nonprofit groups, the academic community, decision-making government officials, and industry. In 2015, the Medication Adherence Alliance convened to review the current landscape of medication adherence. The group then established three working groups that will develop recommendations for shifting toward solutions-oriented science.

Commentary of expert opinion: From the perspective of the Medication Adherence Alliance, the objective of this commentary is to describe changes in the US landscape of medication adherence, framing the evolving field in the context of a recent think tank meeting of experts in the field of medication adherence.

Keywords: medication adherence, health planning recommendations, chronic disease

\section{Introduction}

According to the US Institute of Medicine, medications are the most common medical intervention, and their potential to both help and harm is vast. ${ }^{1}$ Timely and continuous use of prescription medicines is key to effective disease management, particularly for chronic conditions. Yet, nonadherence to prescription medications remains a serious, common, and costly problem. ${ }^{2-4}$ Over half of American adults are nonadherent, leading to annual avoidable health care costs ranging in hundreds of billions of dollars. ${ }^{5}$ While many interventions and programs have demonstrated improvements in specific settings, ${ }^{6-8}$ there is no singular effective solution to improve medication nonadherence, as there is no one outstanding explanation for nonadherent behavior. The objective of this commentary is to describe changes in the landscape of medication adherence, framing the evolving field in the context of a recent think tank meeting of predominately US experts in the field of medication adherence.

Correspondence: Hayden B Boswort Center for Health Services Research in Primary Care, Durham Veterans Affairs Medical Center, 4 II West Chapel Hill Street, Suite 600, Durham, NC 2770I, USA

$\mathrm{Tel}+\mathrm{I} 9192866936$

$\mathrm{Fax}+19194165836$

Email boswo00I@mc.duke.edu

\section{Convening of medication adherence experts}

In 2011, medication adherence leaders organized a 2-day think tank in which key experts, including consumer advocacy groups, community health providers, nonprofit groups, the academic community, decision-making government officials, and industry 
representatives, met to consider the current state of medication nonadherence and provide practical recommendations for shifting toward solutions-oriented science. ${ }^{9}$ The group coined themselves the "Medication Adherence Alliance" (or "Alliance"). The overarching goal of the Alliance is to assemble a body of medication adherence experts to comment and provide feedback on current and proposed legislation and policies potentially affecting medication adherence. As an outcome of this initial meeting, the Alliance developed a call to action that summarized three basic assumptions of the think tank participants. ${ }^{9}$ In brief, first, the Alliance expected that proven strategies should be identified and integrated in a tailored, multicomponent manner. Second, it was presumed that medication adherence is a shared objective in which providers, payers, patients, and the health care system at large share roles and responsibilities. These participants included multiple members of the health care team throughout the continuum of care, individuals who provide patient social support (eg, family), community liaisons, health care payers and providers, and policy makers. Third, it was believed that while quality indicators for adherence-related outcomes and emerging standards for health information technology would spawn national-level change, the Alliance might proactively improve adherence through strategic, participatory action at local levels in their own health care environments. ${ }^{9}$

Nearly 4 years later, the think tank reconvened (2015) for a second 2-day session. The goal of the meeting was to consider if, and how, the US landscape of medication adherence had evolved since the initial call to action. The second think tank was also structured around three key concepts. First, how had the problem of medication adherence evolved in the previous 4 years? For example, how had financial incentives shaped medication adherence priorities? Second, were we closer to identifying successful intervention strategies? For example, how could we leverage information technology, existing data sets, and interoperability standards to improve and automate medication adherence measurement? And finally, could we develop specific recommendations to transform clinical care? What should our revised priorities be in order to advance scientific knowledge and develop evidence-based policies, and ultimately provider improved patient outcomes? Throughout this updated commentary, we address each of these three key concepts. We also discuss perceived future directions for the Alliance and, more broadly, the field of medication adherence.

\section{How has medication adherence evolved?}

Since the initial think tank meeting (2011), there is heightened awareness of medication adherence as a problem on both the national ${ }^{2-4}$ and international stage..$^{2,10,11}$ There is also increasing attention on raising awareness about the problem of poor adherence by educating and engaging patients, their families, and caregivers. ${ }^{5}$ Despite much attention and the development of numerous interventions aimed at improving medication adherence, ${ }^{6-8}$ adherence generally remains low and is a continuing public health concern. As a result, there are continued consequences with regard to morbidity/mortality burden and health care costs. There are, however, new possible solutions to improve medication adherence including 1) policy-based interventions (eg, incentive reform), 2) emerging technologies, and 3) patient-level interventions (Table 1).

Table I Potential strategies to improve medication adherence

\begin{tabular}{|c|c|c|}
\hline Strategy & Intervention level & Example(s) \\
\hline Policy-based interventions & Health policy & $\begin{array}{l}\text { - Incentive reform } \\
\text { - Value-based insurance designs } \\
\text { - MTM } \\
\text { - Medicare five-star quality ratings and medication adherence measurement }{ }^{16}\end{array}$ \\
\hline Access interventions & $\begin{array}{l}\text { Individual and health care } \\
\text { system level }\end{array}$ & $\begin{array}{l}\text { - Full prescription coverage programs (eg, MI-FREEE trial) } \\
\text { - Education for health care professionals in promoting behavior change }\end{array}$ \\
\hline $\begin{array}{l}\text { Internet (eHealth) and mobile } \\
\text { health (mHealth) technologies }\end{array}$ & $\begin{array}{l}\text { Individual and health care } \\
\text { system level }\end{array}$ & $\begin{array}{l}\text { - Text messaging } \\
\text { - Interactive voice response } \\
\text { - Smartphone applications } \\
\text { - Pill-monitoring technologies } \\
\text { - New capabilities in electronic health record software }\end{array}$ \\
\hline Care coordination & Health care system level & $\begin{array}{l}\text { - MTM } \\
\text { - Integrated electronic health record systems } \\
\text { - Medication synchronization }\end{array}$ \\
\hline Health literacy interventions & $\begin{array}{l}\text { Individual and health care } \\
\text { system level }\end{array}$ & - Meducation ${ }^{\circledast}$ by Polyglot Systems, Inc. ${ }^{37}$ \\
\hline
\end{tabular}

Abbreviation: MTM, medication therapy management. 
Although the effects may vary by disease burden, therapeutic area, or other factors, ${ }^{12}$ it is widely believed that improving medication adherence will result in improved individual- and population-level health and reduced health care spending. ${ }^{13,14}$ As a result, the Centers for Medicare Medicaid Services developed a five-star rating system. Under this system, facilities are rated with between one (poorest quality) and five (best quality) stars, indicating their care quality. ${ }^{15}$ The rating is based on a number of factors such as health inspections, staffing, and quality measures. Quality measures are grouped in four categories, measures of: 1) operational excellence; 2) Medicare Part D (eg, Medicare prescription drug coverage); 3) clinical quality measures; and 4) operational measures. Medication adherence is a key component of the Medicare Part D quality measure, indicating that improving adherence is critical to ensure a Centers for Medicare and Medicaid Services five-star rating. ${ }^{16}$

This policy shift to include a focus on medication adherence is timely. Patients insured by Medicare supplements take an average of approximately seven unique medications, resulting in substantial out-of-pocket cost burden which may increase nonadherence. ${ }^{17}$ In fact, cost-saving strategies are widely used by patients insured by Medicare Part D. ${ }^{17}$ The hope is that revisions to Medicare Part D will swing health care systems' attention toward continual medication adherence measurement, thus better coordinating with individual patients to address the unique factors contributing to their nonadherence. If this approach is successful, improving adherence may also reduce overall health care costs. As one example, among Medicare beneficiaries with chronic heart failure and diabetes, researchers determined that higher levels of medication adherence were associated with decreased costs in Medicare spending, generally savings beyond drug costs. ${ }^{13,14}$

There is renewed interest in policy-based interventions. A switch in incentive reforms could make medication adherence improvement more imperative. One example of a policy-based intervention is incentive reform in the form of value-based insurance designs. "A value-based insurance design encourages the use of services when the clinical benefits exceed the cost and likewise discourage the use of services when the benefits do not justify the cost". ${ }^{18}$ In the context of medication adherence, this often translates to reducing or eliminating patients' out-of-pocket costs for certain efficacious medications, with the goal of improving their adherence. The notion is that the medical cost savings, via improved clinical outcomes and decreased utilization of medical services, should be sufficiently high to outweigh the drug costs and that of reduced copayments. Blue Cross Blue Shield of North Carolina implemented a value-based insurance design in 2008, for example, which resulted in improved medication adherence and modestly decreased hospitalizations. ${ }^{19,20}$ Despite these positive outcomes, the investment in program cost exceeded its health care savings. ${ }^{20}$ These disappointing results notwithstanding, other similar programs have shown promise. ${ }^{21-23}$

There is evidence that value-based medication adherence programs can be efficacious. As one such example, researchers from Harvard University conducted a randomized clinical trial among patients discharged after myocardial infarction. Patients were randomized at the level of their health care insurer to either usual prescription coverage or full prescription coverage..$^{24}$ The authors reported that adherence ranged from approximately $36 \%$ to $49 \%$ in the usual prescription coverage group and were 4-6 percentage points higher in the full-coverage group..$^{24}$ While this is a significant improvement, it may not be practical or sustainable to provide full prescription coverage for an entire population. While full-coverage programs and value-based insurance designs remain promising, more research is needed to understand how appropriately designed programs can generate cost savings while maintaining patient access.

A widespread intervention approach for appropriate medication use is medication therapy management (MTM), which is reimbursable under Medicare Part D. MTM involves a comprehensive set of services including medication review, follow-up, and care coordination. While this is a resourceintensive intervention, a recent report developed by Agency for Health Research and Quality (AHRQ) suggests that the evidence base supporting MTM is low. ${ }^{25}$ One aspect of MTM is medication synchronization. Medication synchronization is the process of aligning a patient's medication refills such that they are all due on the same day. The timing of the refills must be done thoughtfully; for example, for many patients, it will be critical that the refill date is scheduled to coincide with their paycheck or social security check. Appropriate medication synchronization has been demonstrated to improve medication adherence among people with chronic conditions. ${ }^{26,27}$

In addition to the evolution of the problem of medication nonadherence, potential solutions for monitoring and measuring adherence are also developing. From both a patient and health care system perspective, there is increased adoption of Internet (eHealth) and mobile health (mHealth) technologies. The potential for monitoring and measuring adherence will enable innovative technologies and will likely further support evidence-based care, patient self-monitoring and 
medication-taking reminders, such as pill-monitoring technologies (including digital pills), mobile health (mHealth) technologies (eg, text messaging, interactive voice response, smartphone applications), and online resources and social media, among others. ${ }^{28}$ From the US health care system side, capabilities in electronic health record software will enable automated detection of primary medication nonadherence or discontinuation using pharmacy fill and claims data. These data can be automatically transmitted back to the prescriber as additional information for managing patients' appropriate use of medication, serving to facilitate further coordination among the health care continuum. A broad array of more affordable front-end technology (eg, that the user directly interacts with) is emerging to directly collect and record patient adherence data. This front-end technology pulls into focus the importance of accurate and predictive data analysis, effective patient communication, and provider counseling opportunities to address the more complicated issues of implementing interventions in "real-world" settings. These technological solutions are important tools, but they should be used within the framework of setting a patient-centered agenda, broadening the scope of adherence interventions to include aspects of medication management that may be beyond the traditional scope of adherence research. ${ }^{29}$ Technology may also shift the way we define adherence. In the policy arena, a dichotomous measure of adherence is often used, but a continuous measure of adherence with consideration for patterns of use may be more meaningful for clinical efforts. As the US landscape of medication adherence evolves, it is critical that we identify existing, successful intervention strategies to improve adherence.

\section{Are we closer to identifying successful intervention strategies?}

Recent systematic reviews have evaluated the impact of specific intervention approaches on improving medication adherence. ${ }^{30-33}$ Conn et al identified that the largest effect sizes were among studies that used electronic medicationmonitoring systems. Other approaches that improved adherence included prompting patients to take their medications (ie, reminders) and linking medication taking with existing habits or behaviors. ${ }^{30}$ There is increasing evidence for the effectiveness of text messaging as a modality to improve medication adherence. When designing interventions delivered via text messages, investigators should consider the content (standardized vs tailored), interaction (one-way vs two-way), timing (along with medication dose or meal), and dose (daily, weekly, or monthly). ${ }^{34}$ However, for patients with a history of medication adherence problems, face-to-face interventions may still work best. ${ }^{30}$

While there have been numerous successful interventions to improve medication adherence, ${ }^{6-8}$ relatively few are implemented and reported beyond the academic research setting; instead, they tend to be isolated to a specific clinical condition or setting and are often only tested in the context of a clinical trial, rather than in a real-world efficacy scenario. Industry stakeholders often develop potentially more practical interventions, but they are often not reported with sufficient detail to enable reproducibility in other health care settings. As an example, CVS Health recently announced a medication synchronization program called ScriptSync ${ }^{\mathrm{TM}}$ that is currently available in all CVS retail pharmacy locations and will soon be available via mailed prescription services. ${ }^{35}$ CVS has a research branch (the CVS Health Research Institute) that often publishes and disseminates information about what works well in their system; however, many industry stakeholders do not take this additional step.

Interventions must also consider cost efficiency and longterm sustainability, value of the intervention to each user, practical factors necessary for implementation in real-world clinical context, and challenges required for dissemination and use on disparate platforms. ${ }^{8,36}$ As an example, with the advent of specialty medications (ie, biologic agents for the treatment of cancer), some requiring high out-of-pocket cost, support for appropriate medication use often becomes embedded in a support infrastructure provided by the drug manufacturer. A sustainable intervention might consider who will incur the cost of supporting a program and ensure buy-in from key stakeholders. Furthermore, adherence interventions tend to be evaluated as part of more complex multidimensional programs, and more information is needed regarding the value of each individual component in order to facilitate optimal care management design. Thus, future intervention designs must emphasize practicality and scalability in designing and testing plans for implementation and dissemination.

\section{Can we develop specific recommendations to transform clinical care?}

The primary outcome of the second Alliance think tank reboot was the development of three work groups. Each work group is focused on an area that the Alliance asserts is critical to improving medication adherence and is currently understudied: 1) a "living" laboratory, 2) medication adherence 
measurement workgroup, and 3) electronic health record workgroup. These workgroups are composed of multidisciplinary teams united for a finite period of time and a specific goal. The living laboratory provides a forum for linking research and industry that has developed innovative products and interventions targeting improved adherence, with health care systems partners who will provide a real clinic environment in which to pilot test their product or intervention. For example, as an initial living laboratory exercise, the Alliance plans to implement Meducation ${ }^{\circledR}$ by Polyglot Systems, Inc. ${ }^{37}$ in select Premier Health System sites. Meducation provides customized visualization of medication schedules available in numerous languages that are specially designed to accommodate patients with low health literacy. ${ }^{37}$ The measurement workgroup is charged with synthesizing and summarizing available methods of measuring adherence (eg, pill cap-monitoring technology, pharmacy refill data, self-report) and providing guidance on when and how each potential source of measurement can be most appropriately used. For example, a clinical trial might be best served with objective pill cap-monitoring data, whereas self-report might be perfectly suitable for providing routine clinical care. The electronic health record workgroup is developing recommendations articulating ways in which electronic health records and supportive systems (eg, pharmacy refill records) can be optimized to support the measurement and improvement of medication adherence.

While the Alliance affirms that addressing these three areas (providing a living laboratory, evaluating adherence measurement tools, and integrating electronic records) have the potential to advance clinical care, the Alliance members also recognize the need for better integration with international partners for a broad perspective. One example of an international partner is the European Society for Patient Adherence, COMpliance and Persistence (ESPACOMP). ${ }^{11}$ ESPACOMP is a predominately European "nonprofit association established to promote the science concerned with the quantitative assessment of what patients do with medicines they have been prescribed". ${ }^{11}$ The group organizes annual symposiums reaching clinical, research, and industry partners focused on medication adherence from multiple countries and continents. The 2015 ESPACOMP annual meeting included abstract submissions from more than 20 countries. ${ }^{38}$ Collaborating with colleagues in other geographic and clinical contexts should be a central priority for designing creative solutions to improve medication adherence, learning from each other, and improving our success as a global community.

\section{Conclusion}

While medication nonadherence remains a problem, it is not an insurmountable one. With increased attention, advancements in technology, and new tools for measurement, there are new opportunities for engaging patients and stakeholders to improve medication adherence like never before. The importance of a multidisciplinary approach to treating and training medication adherence cannot be overstated and is being used to promote adherence. ${ }^{39}$ This multidisciplinary approach aligns with the increasing use of primary care medical homes. Any one of these areas represents an area ripe for rigorous research and in-depth review. Also of central importance, but not a focus of the Alliance, is providing educational opportunities and tools for health care professionals. The Alliance is primarily focused on adherence efforts within the US; however, there are many successful adherence interventions occurring in other contexts.

We assert that the products resulting from the Alliance will be useful to a myriad of stakeholders to foster engagement, collaboration, and implementation of effective programs. A critical premise lies in the belief that improved medication adherence provides better patient outcomes and value to the health care system. To be successful, we must harness this momentum wisely, engaging stakeholders, collaborating with international partners, and designing solutions with implementation and sustainability at the forefront.

\section{Acknowledgments}

This manuscript was written on behalf of the Medication Adherence Alliance: Phil Mendys, PharmD, FAHA, CPP; Sloane Salzburg, MS; Charles Lee, MD; J Samantha Dougherty, PhD; Ryan J Shaw, PhD, RN; Ralph G Brindis, MD, MPH; Walid F Gellad, MD, MPH; Bernard Vrijens, PhD; Elizabeth Whalley Buono, RN, MBA, JD; Rebecca Burkholder, JD; P Michael Ho, MD, PhD. We thank Troy Trygstad and John Fastenau for their feedback and review.

Experts from the following organizations participated in the 2015 Think Tank: AstraZeneca, Bristol-Myers Squibb, Centers for Medicare and Medicaid, Community Care of North Carolina, Duke Clinical Research Institute, Duke University Medical Center, US Food and Drug Administration, Janssen Pharmaceuticals, MWV Healthcare, National Consumers League, National Institutes of Health (NIH), NIH Adherence Network, Patient-Centered Outcomes Research Institute, Pfizer, Pharmacy Quality Alliance, PhRMA, Polyglot Systems, Inc., Premier Healthcare Innovators Collaborative, Prescriptions for a Healthy America, The Network for Excellence in Health Innovation, University of California at San 
Francisco, University of Houston, University of Pittsburgh, and VA Eastern Colorado Health Care System.

Dr Zullig is supported by a VA Health Services Research and Development (HSR\&D) Career Development Award (CDA 13-025). Dr Bosworth is supported by a Research Career Scientist Award from VA Health Service Research and Development (VA HSR\&D 08-27). The views in this article are those of the authors and do not necessarily represent the views of the Department of Veterans Affairs, Duke University, or individual organizations participating in the Medication Adherence Alliance.

\section{Disclosure}

The authors report no conflicts of interest in this work.

\section{References}

1. Institute of Medicine. Pharmaceuticals: the good and the bad. Informing the Future: Critical Issues in Health. Washington, DC: National Academies Press; 2007:13.

2. Brown MT, Bussell JK. Medication adherence: WHO cares? Mayo Clin Proc. 2011;86(4):304-314.

3. Ho PM, Bryson CL, Rumsfeld JS. Medication adherence: its importance in cardiovascular outcomes. Circulation. 2009;119(23):3028-3035.

4. Osterberg L, Blaschke T. Adherence to medication. $N$ Engl J Med. 2005;353(5):487-497.

5. Aitken M, Valkova S. Avoidable Costs in US Healthcare: The $\$ 200$ Billion Opportunity from Using Medicines More Responsibly. Parsippany, NJ: IMS Institute for Healthcare Informatics; 2013.

6. van Dalem J, Krass I, Aslani P. Interventions promoting adherence to cardiovascular medicines. Int J Clin Pharm. 2012;34(2):295-311.

7. Zullig LL, Bosworth HB. Behavioral interventions to improve hypertension control in the veterans affairs healthcare system. J Clin Hypertens (Greenwich). 2014;16(11):827-837.

8. Zullig LL, Gellad WF, Moaddeb J, et al. Improving diabetes medication adherence: successful, scalable interventions. Patient Prefer Adherence. 2015;9:139-149.

9. Bosworth HB, Granger BB, Mendys P, et al. Medication adherence: a call for action. Am Heart J. 2011;162(3):412-424.

10. McKenzie SJ, McLaughlin D, Clark J, Doi SA. The burden of nonadherence to cardiovascular medications among the aging population in Australia: a meta-analysis. Drugs Aging. 2015;32(3):217-225.

11. Schneider MP, Bouvy M. The ESPACOMP and its role in promoting knowledge and competencies in the matter of patient adherence. Int $J$ Clin Pharm. 2014;36(1):8-9.

12. Stuart BC, Dai M, Xu J, Loh FH, S Dougherty J. Does good medication adherence really save payers money? Med Care. 2015;53(6): $517-523$.

13. Lopert R, Shoemaker JS, Davidoff A, et al. Medication adherence and Medicare expenditure among beneficiaries with heart failure. Am J Manag Care. 2012;18(9):556-563.

14. Stuart B, Davidoff A, Lopert R, Shaffer T, Samantha Shoemaker J, Lloyd J. Does medication adherence lower Medicare spending among beneficiaries with diabetes? Health Serv Res. 2011;46(4):1180-1199.

15. Centers for Medicare \& Medicaid Services [webpage on the Internet]. Five-Star Quality Rating System [updated February 24, 2016]. Available from: https://www.cms.gov/medicare/provider-enrollmentand-certification/certificationandcomplianc/fsqrs.html. Accessed March 2, 2016.

16. Lau DT, Briesacher BA, Touchette DR, Stubbings J, Ng JH. Medicare Part D and quality of prescription medication use in older adults. Drugs Aging. 2011;28(10):797-807.
17. Musich S, Cheng Y, Wang SS, Hommer CE, Hawkins K, Yeh CS. Pharmaceutical cost-saving strategies and their association with medication adherence in a Medicare supplement population. J Gen Intern Med. 2015;30(8):1208-1214.

18. Chernew ME, Rosen AB, Fendrick AM. Value-based insurance design. Health Aff (Millwood). 2007;26(2):w195-w203.

19. Maciejewski ML, Farley JF, Parker J, Wansink D. Copayment reductions generate greater medication adherence in targeted patients. Health Aff (Millwood). 2010;29(11):2002-2008.

20. Maciejewski ML, Wansink D, Lindquist JH, Parker JC, Farley JF. Value-based insurance design program in north Carolina increased medication adherence but was not cost neutral. Health Aff (Millwood). 2014; 33(2):300-308.

21. Choudhry NK, Fischer MA, Avorn J, et al. At Pitney Bowes, valuebased insurance design cut copayments and increased drug adherence. Health Aff (Millwood). 2010;29(11):1995-2001.

22. Choudhry NK, Fischer MA, Smith BF, et al. Five features of value-based insurance design plans were associated with higher rates of medication adherence. Health Aff (Millwood). 2014;33(3):493-501.

23. Volpp KG, Troxel AB, Long JA, et al. A randomized controlled trial of co-payment elimination: the CHORD trial. Am J Manag Care. 2015; 21(8):e455-e464.

24. Choudhry NK, Avorn J, Glynn RJ, et al. Full coverage for preventive medications after myocardial infarction. N Engl J Med. 2011;365(22): 2088-2097.

25. Viswanathan M, Kahwati LC, Golin CE, et al. Medication Therapy Management Interventions in Outpatient Settings. Rockville, MD: Agency for Healthcare Research and Quality; 2014.

26. Holdford D, Saxena K. Impact of appointment-based medication synchronization on existing users of chronic medications. J Manag Care Spec Pharm. 2015;21(8):662-669.

27. Holdford DA, Inocencio TJ. Adherence and persistence associated with an appointment-based medication synchronization program. $J \mathrm{Am}$ Pharm Assoc. 2013;53(6):576-583.

28. Zullig L, Shaw R, Bosworth H. The application of technology to medication management and adherence. In: Marsch L, Lord S, Dallery J, editors. Leveraging Technology to Transform Behavioral Healthcare. New York, NY: Oxford University Press; 2014:81-94.

29. McMullen CK, Safford MM, Bosworth HB, et al. Patient-centered priorities for improving medication management and adherence. Patient Educ Couns. 2015;98(1):102-110.

30. Conn VS, Ruppar TM, Enriquez M, Cooper P. Medication adherence interventions that target subjects with adherence problems: systematic review and meta-analysis. Res Social Adm Pharm. 2016; 12(2):218-246.

31. Costa E, Giardini A, Savin M, et al. Interventional tools to improve medication adherence: review of literature. Patient Prefer Adherence. 2015;9:1303-1314.

32. Kripalani S, Yao X, Haynes RB. Interventions to enhance medication adherence in chronic medical conditions: a systematic review. Arch Intern Med. 2007;167(6):540-550.

33. Nieuwlaat R, Wilczynski N, Navarro T, et al. Interventions for enhancing medication adherence. Cochrane Database Syst Rev. 2014; 11:CD000011.

34. DeKoekkoek T, Given B, Given CW, Ridenour K, Schueller M, Spoelstra SL. mHealth SMS text messaging interventions and to promote medication adherence: an integrative review. J Clin Nurs. 2015; 24(19-20):2722-2735.

35. PR Newswire [webpage on the Internet]. CVS Health Launches ScriptSync ${ }^{\text {TM }}$ to Make Medication Adherence Easier for Patients who have Multiple Prescriptions [updated August 11, 2015]. Available from: http://www.prnewswire.com/news-releases/cvs-health-launches-scriptsynctm-to-make-medication-adherence-easier-for-patients-who-havemultiple-prescriptions-300126598.html. Accessed March 2, 2016.

36. Zullig LL, Peterson ED, Bosworth HB. Ingredients of successful interventions to improve medication adherence. JAMA. 2013;310(24): 2611-2612. 
37. "Polyglot" Health through Understanding [homepage on the Internet]. Available from: http://www.pgsi.com/. Accessed July 31, 2015.

38. Krousel-Wood M, Islam T, Webber LS, Re RN, Morisky DE, Muntner P. New medication adherence scale versus pharmacy fill rates in seniors with hypertension. Am J Manag Care. 2009;15(1):59-66.
39. Lelubre M, Kamal S, Genre N, et al. Interdisciplinary medication adherence program: the example of a University Community Pharmacy in Switzerland. Biomed Res Int. 2015;2015:103546.

\section{Publish your work in this journal}

Patient Preference and Adherence is an international, peer-reviewed, open access journal that focuses on the growing importance of patient preference and adherence throughout the therapeutic continuum. Patient satisfaction, acceptability, quality of life, compliance, persistence and their role in developing new therapeutic modalities and compounds to optimize clinical outcomes for existing disease states are major areas of interest for the journal. This journal has been accepted for indexing on PubMed Central. The manuscript management system is completely online and includes a very quick and fair peer-review system, which is all easy to use. Visit http://www. dovepress.com/testimonials.php to read real quotes from published authors.

\footnotetext{
Submit your manuscript here: http://www.dovepress.com/patient-preference-and-adherence-journal
} 